\title{
Case - Tension hydrocele: A rare cause of acute scrotal pain
}

Christopher Bitcon; Joshua White; Ashley Cox; Tom Skinner

Dalhousie University, Halifax, NS, Canada

Cite as: Can Urol Assoc J 2020 February 4; Epub ahead of print. http://dx.doi.org/10.5489/cuaj.6363

Published online February 4, 2020

$* * *$

\section{Case}

An otherwise healthy 50-year old male presented to the outpatient urology clinic for evaluation of a swollen left hemiscrotum. The initial presentation was painless but was beginning to interfere with the patient's enjoyment of daily activities. There was no history of trauma, sexually transmitted infection (STI), or acute testicular/scrotal pain. Examination revealed a large, firm left hemiscrotum. The left testicle was non-palpable due to the tense hydrocele sac. Transillumination was demonstrated. His right testicle was palpable and normal within a small right-sided hydrocele. There was no evidence of cellulitis or scrotal discoloration. The remainder of the physical exam was within normal limits. A routine preoperative scrotal ultrasound was performed revealing a large simple left hydrocele with normal vascular flow to the left testicle (Figure 1). A small right hydrocele was also detected with a normal right testicle.

The patient was re-evaluated in the urology clinic 2 days later to establish a treatment plan. At this visit, the patient described a 24-hour history of increasing left orchialgia. The pain was described as throbbing/aching in nature and radiated up to the level of the inguinal ligament. The patient also described a new sense of tightness particularly in the inguinal canal. The pain was positional, prevented the patient from sleeping, and was associated with mild nausea. Repeat physical examination revealed a more tense hydrocele than previously appreciated. There was again, no evidence of scrotal infection or discoloration and no inguinal lymphadenopathy. The right hemiscrotum was unchanged. Clinically, the patient appeared significantly more uncomfortable so a repeat, urgent testicular ultrasound was ordered.

Repeat Doppler ultrasonography revealed decreased blood flow to the left testicle compared to the right testicle. There was also decreased blood flow to the left testicle compared to the ultrasound performed 2 days prior (Figure 2). Fortunately, there was no evidence of 
infarct. These findings were communicated with the patient who ultimately consented to undergo semi-urgent scrotal exploration.

Under general anesthesia, a transverse scrotal incision was made. The dartos was incised with electrocautery then bluntly dissected away from the tunica vaginalis to avoid compromising its integrity. The tunica was delivered through the left hemiscrotum (Figure 3). The tunica was under immense pressure and was very firm on exam. There was evidence of vasocongestion along the ventral aspect. The tunica vaginalis was then incised and serous fluid erupted under pressure. This was drained and the testicle was inspected. The testicle appeared healthy without evidence of compromised blood flow. A Jaboulay technique was performed and the hemiscrotum was closed.

Doppler ultrasonography was performed 14 days post-operatively (Figure 4). There was restoration of equal blood flow to the testicles bilaterally. In follow-up this gentleman had complete resolution of his orchalgia without evidence of hydrocele recurrence.

\section{Discussion}

Hydroceles result from an abnormal collection of fluid between the visceral and parietal layers of the tunica vaginalis. They may be either congenital or acquired. Treatment is generally considered on an elective basis and is sought when the size impairs daily function, results in pain, or causes skin irritation to the scrotum or thigh.

There is evidence to suggest that hydroceles may effect both arterial and venous testicular blood flow. ${ }^{3,4}$ An increase in hydrocele volume causes an increase in intratesticular pressure. There is a point at which the intratesticular pressure surpasses the perfusion pressures of the testicular vasculature. This impediment is first seen in venous drainage, but can eventually lead to impaired arterial inflow. We found four such cases reported in the literature, and all four reported that normal blood flow was restored after hydrocelectomy., ${ }^{2,5-7}$

This rare phenomenon has been termed "tension hydrocele" and the mechanics are analogous to a compartment syndrome. Zawaideh et al. speculate that the acute pain that accompanies such phenomena is a combination of the duration of the hydrocele and the acute change in intratesticular pressure, though the contribution of each factor is unknown. ${ }^{8}$

To our knowledge, this is the first case report with radiographic evidence of previously normal testicular perfusion that became impaired with increased hydrocele size. We were also able to demonstrate resolution post-surgery. Due to the lack of evidence supporting other acute scrotal or testicular pathology and the radiographic findings that correlated with the patient's clinical presentation, we conclude that such symptoms were in fact caused by an acute tension hydrocele. 


\section{References}

1. Douglas J, Hicks J, Manners J, et al. A pressing diagnosis - a compromised testicle secondary to compartment syndrome. Ann R Coll Surg Engl. 2008;90:W6-W8. doi:10.1308/147870808X 257184

2. Bertolotto M, Cantisani V, Valentino $M$ et al. Pitfalls in Imaging for Acute Scrotal Pathology. Semin Roentgenol. 2016;51:60-9. doi:10.1053/j.ro.2016.02.012

3. Mihmanli I, Kantarci F, Kulaksizoglu H, et al. Testicular size and vascular resistance before and after hydrocelectomy. AJR. 2004;183:1379-1385. doi:10.2214/ajr.183.5.1831379

4. Turgut AT, Unsal A, Ozden E, et Al. Unilateral idiopathic hydrocele has a substantial effect on the ipsilateral testicular geometry and resistivity indices. J Ultrasound Med. 2006;25(7):837-43. doi:10.7863/jum.2006.25.7.837

5. Nye PJ, Prati RC. Idiopathic hydrocele and absent testicular diastolic flow. J Clin Ultrasound. 1997;25:43-46. doi: 10.1002/(SICI)1097-0096(19970 1)25:1<43::AIDJCU8 $>3.0$

6. Wright LA, Gerscovich EO, Corwin MT, et al. Tension hydrocele: additional cause of ischemia of the testis. J Ultrasound Med. 2012;31(12):2041-3. doi:10.7863/jum.2012.31.12.204112.

7. Dagrosa LM, McMenaman KS, Pais VM Jr. Tension Hydrocele: An Unusual Cause of Acute Scrotal Pain. Pediatr Emerg Care. 2015;31(8):584-5. doi:10.1097/PEC.0000000000000283

8. Zawaideh JP, Bertolotto M, Giannoni M et al. Tension hydrocele as an additional cause of acute scrotum: case series and literature review. Abdom Radiol. 2019. doi:10.1007/s00261-019-01991-8

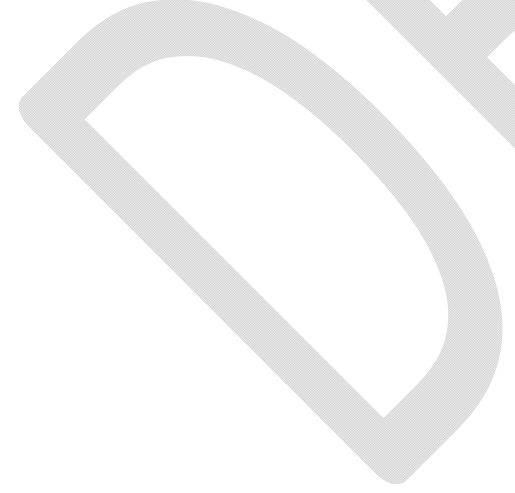




\section{Figures and Tables}

Fig. 1. Elective Doppler ultrasonography of the left testicle displaying normal perfusion.

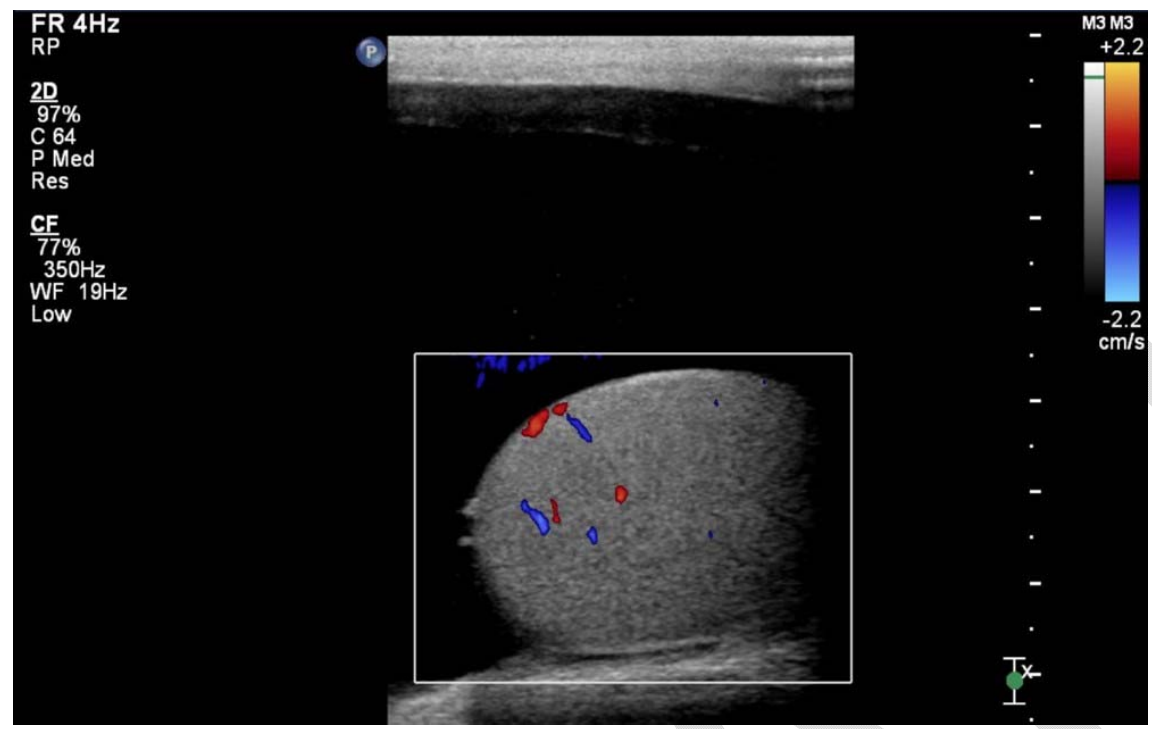

Fig. 2. Repeat Doppler ultrasonography of the left testicle displaying reduced perfusion.

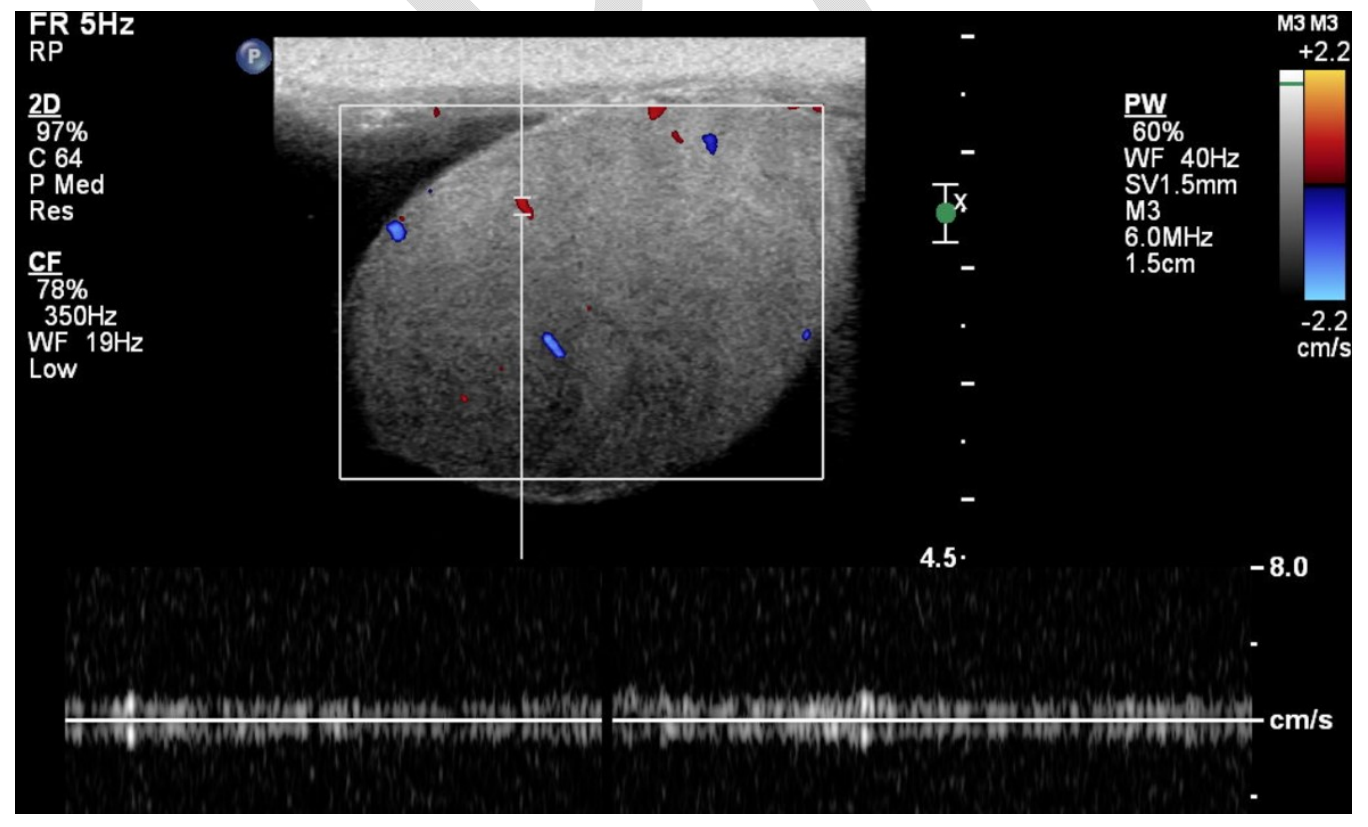


Fig. 3. Large left hydrocele with the tunica vaginalis intact (left) and evidence of vasocongestion (right). The approximate measurement was $12.0 \mathrm{~cm}$ x $9.6 \mathrm{~cm} \times 7.5 \mathrm{~cm}$.

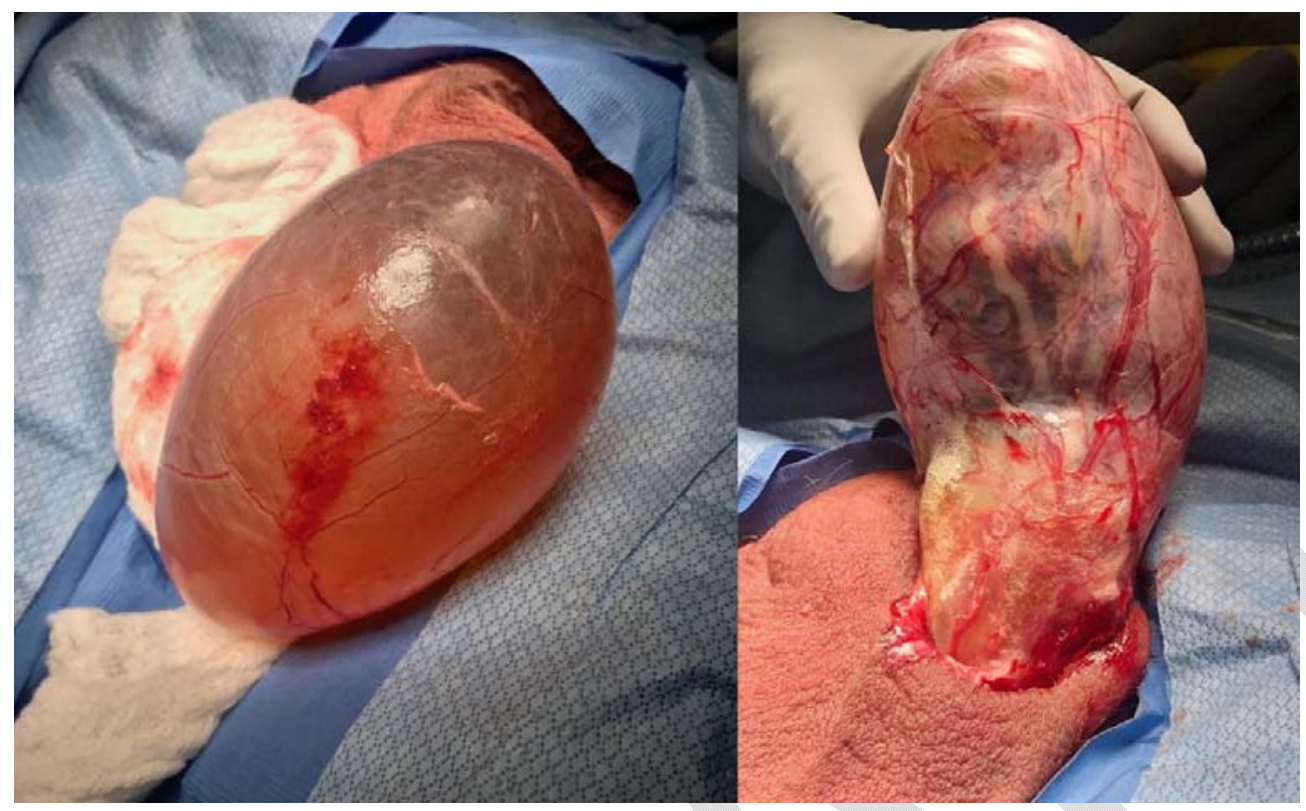

Fig. 4. Postoperative Doppler ultrasonography of the left and right testicle showing restored blood flow of the left testicle and symmetric blood flow, bilaterally.

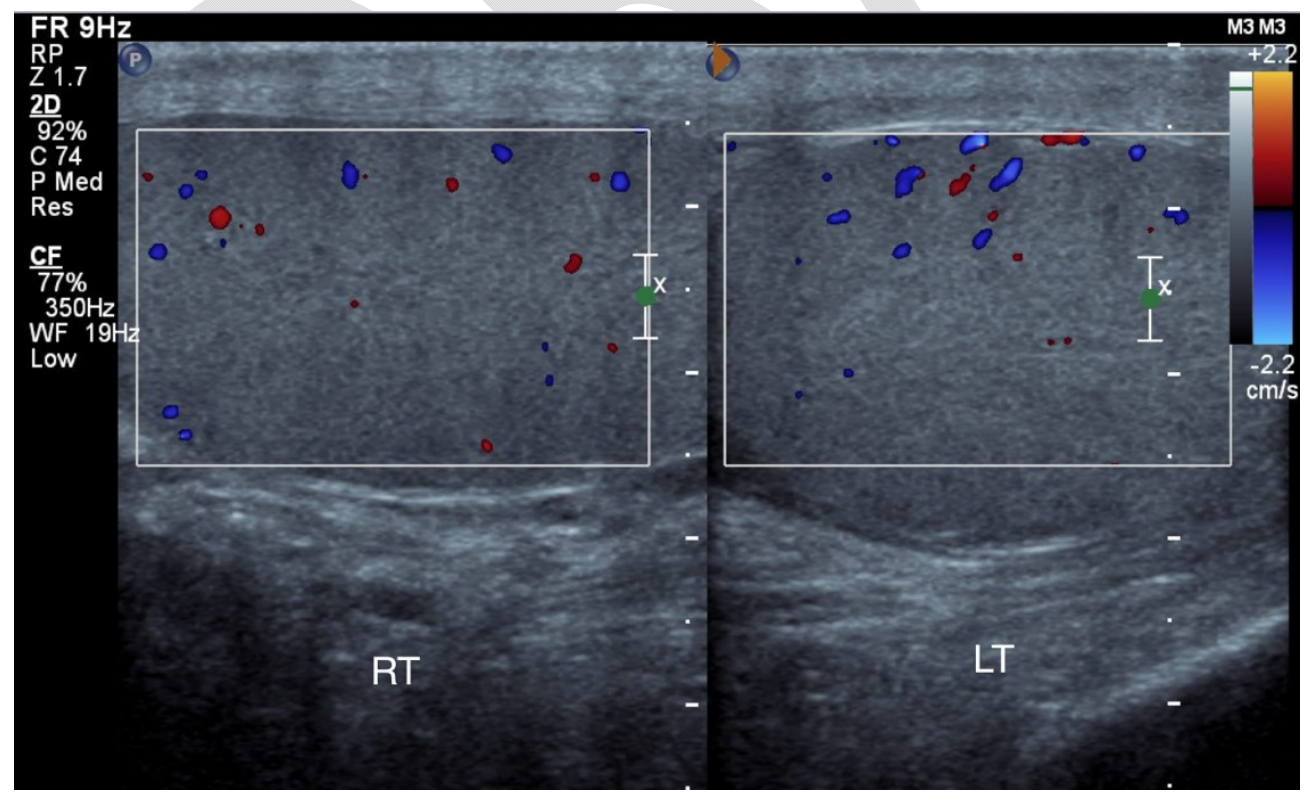

